\title{
O canto na cidade calada à força: poder simbólico na poesia anticolonial moçambicana
}

The sing in the city silenced: symbolic power in Mozambican anticolonial poetry

Luana Soares de Souza

Doutoranda em Estudos Literários pela Universidade do Estado de Mato Grosso, campus

(i)hitps://orcid.org/0000-0002-9218-3187
RESUMO: A partir de poemas de José Craveirinha e Noémia de Sousa, ícones da poesia anticolonial moçambicana, serão discutidas as formas de luta pelo poder simbólico. Analisando a poesia desses escritores, é possível observar que a luta se constrói tanto no campo objetivo (luta explícita, material e política), quanto no campo simbólico (luta pelo espaço, cultura e símbolos sociais). Segundo Pierre Bourdieu (1989), os campos sejam eles políticos, literários, religiosos ou científicos - estão em constante disputa, que é derivada da desigualdade de capital entre os agentes (dominantes ou dominados), que lutam pela conservação ou subversão das estruturas. Dessa forma, buscou-se analisar nos poemas como se construiu a luta pela palavra que foi aprisionada pelos agentes dominantes durante o período colonial.

Palavras-chave: Moçambique; Teoria das Estruturas; Poder simbólico; Colonização; Poesia.

ABSTRACT: From the poems of José Craveirinha and Noémia de Sousa, icons of Mozambican anticolonial poetry, the forms of struggle for symbolic power will be discussed. Analyzing the poetry of the Mozambican writers in question, it is possible to observe that the struggle is built both in the objective field (explicit struggle, material and political), and in the symbolic field (struggle for space, culture and social symbols). According to Pierre Bourdieu (1989), the fields - be they political, literary, religious or scientific - are in constant dispute, which is derived from the inequality of capital between the agents (dominant or dominated), that fight for the conservation or subversion of the structures. In this way, it is sought to analyze in the poems how the struggle for the word occurs that was imprisoned by the dominant agents during the colonial period.

Keywords: Mozambique; Theory of Structures; Symbolic power; Colonization; Poetry. 


\section{Palavras, agentes e poder simbólico}

s palavras possuem uma carga de capital simbólico e estão em disputa nos territórios linguísticos. Dessa forma, as palavras dos grupos dominados confrontam-se com as dos grupos dominantes criando tensões na busca pela voz, poder e legitimidade. A luta dos agentes sociais propõe um exercício de (re)contar a história através das palavras, a partir de determinadas perspectivas ideológicas. Para Bourdieu, o poder das palavras é o "poder de manter a ordem ou de a subverter" (1989, p. 15), logo, é preciso compreender que a forma como as palavras estão organizadas no mundo tem relação umbilical com a classe social dominante. 0 modo como analisamos e classificamos as coisas, os objetos e as relações é, muitas vezes, determinado pela perspectiva hegemônica, ou seja, pelo prisma do grupo dominante, visto que quem domina as relações econômicas, domina as relações simbólicas. Assim, reconstruir uma semântica, produzir novas palavras, calibrar sentidos, é uma forma de subverter as estruturas sociais.

A história oficial é a história contada pelos vencedores. Esse pressuposto implica a análise de que existem outras histórias, outras narrativas que foram esquecidas ou silenciadas. Assim, a história é um conjunto de olhares construído de acordo com os interesses de quem a conta: "A história é objeto de uma construção cujo lugar não é o tempo homogêneo e vazio, mas preenchido de 'tempo de agora'” (BENJAMIN, 2012, p. 249). Portanto, a questão que se coloca não é reformular a história, mas criar novas análises e leituras sobre ela, e isso exige "escovar a história a contrapelo" (BENJAMIN, 2012, p. 245).

Analisar a história requer inscrever o passado. Para Benjamin, "o passado só se deixa capturar como imagem que relampeja irreversivelmente no momento de sua conhecibilidade" (2012, p. 243) e para Ki-Zerbo "a imagem do passado não nos chega de modo claro e estável como num espelho de boa qualidade, mas como um reflexo fugaz que dança sobre a agitação da água" (2010, p. 39). Se o passado é relâmpago - imagem instantânea - e água em movimento, analisá-lo torna-se uma tarefa delicada, pois ele não se apresenta concreta e objetivamente, mas como resultado de dinâmicas e ângulos. O que nos cabe é analisar profundamente esses movimentos levantando o tapete da história, varrendo o véu das ideologias.

Se a história e o passado são feitos de acontecimentos, mas também de palavras, e essas palavras são determinadas e contaminadas pelas relações de poder, seria necessário lutar pelas palavras a fim de que elas correspondam inteiramente a uma coletividade. As palavras não estão aleatoriamente dispostas no mundo; elas estão alinhadas a um modo de pensar e agir. Conforme Sartre, palavra e práxis caminham juntas: “(...) a cada palavra que digo, engajo-me um pouco mais no mundo e, ao mesmo tempo, passo a emergir dele um pouco mais, já que o ultrapasso na direção do porvir" (2015, p. 28).

Partindo do pressuposto de que as palavras fazem parte de um repertório simbólico, o pensamento de Bourdieu será utilizado para analisar os conflitos objetivos e simbólicos entre diferentes segmentos sociais. Para tanto é importante delimitar alguns dos conceitos fundamentais do teórico. Ele observa as estruturas sociais, suas dinâmicas, os agentes envolvidos e o que compõe esses agentes. Para ele, o agente não atua individualmente, sendo produto de uma condição de existência, consciência, prática e ideologia. $\mathrm{O}$ agente está situado em um campo, que não é necessariamente uma estrutura física, mas um microcosmo social (BOURDIEU, 1989, p. 59). Nesse campo, invariavelmente ocorre luta, já que os agentes possuem capitais desproporcionais. Seguindo a linha do marxismo dialético, Bourdieu ultrapassa a noção de capital econômico, estabelecendo o capital simbólico que seria o acúmulo de conhecimentos, habilidades, títulos, línguas, etc. 
Para ele a luta se estabelece no campo econômico, mas não apenas. Em síntese, a luta simbólica torna-se tão importante quanto a luta pelo capital econômico.

As diferentes classes e fracções de classes estão envolvidas numa luta propriamente simbólica para imporem a definição do mundo social mais conforme aos seus interesses, e imporem o campo das tomadas de posições ideológicas reproduzindo em forma transfigurada o campo das posições sociais (BOURDIEU, 1989, p. 11).

Em processos objetivos de luta ocorrem simultaneamente processos de luta simbólica, seja através da luta pela comunicação, pelas palavras, pela língua, pela arte, ou seja, pelo capital simbólico. Portanto, enquanto a luta política é aberta, a luta simbólica é implícita. Nas palavras de Bourdieu (1989), a respeito do poder simbólico,

(...) é necessário saber descobri-lo onde ele se deixar ver menos, onde ele é mais completamente ignorado, portanto, reconhecido: o poder simbólico é, com efeito, esse poder invisível o qual só pode ser exercido com a cumplicidade daqueles que não querem saber que lhe estão sujeitos ou mesmo que o exercem (BOURDIEU, 1989, p. 7).

O poder simbólico está impregnado no invisível: nas palavras, na literatura, na música, nas narrativas, na academia, nas escolas, nas estátuas, nos nomes das ruas e viadutos. Esse poder camufla-se nas instituições, nas relações sociais e nas imagens. Portanto, a literatura em si é poder simbólico, podendo fortalecer ou enfraquecer determinado grupo social. Em processos de luta objetiva, ela se torna uma ferramenta poderosa de percepção e denúncia de uma realidade. Dessa maneira, o escritor que se entrincheira na luta simbólica está, ao manipular as palavras, buscando criar ou reformular a história, restituindo poder simbólico a um grupo de agentes.

\section{Poder simbólico e as lutas anticoloniais: a palavra como arma}

Durante o período colonial, no continente africano, o grupo dominante utilizou uma certa narrativa para construir o imaginário de que os colonizados eram inferiores, pois possuíam um saber diferente do mundo europeu. Segundo Mbembe, a Europa recorreu a um processo de "efabulação" (2014, p. 26) sobre os colonizados para que mantivesse sua hegemonia e domínio que se expressava tanto na violência física, atmosférica e psicológica, como na violência simbólica, a exemplo da imposição da língua da metrópole e a constante negação das línguas autóctones, e a repressão aos cultos religiosos populares, visando fortalecer a religiosidade europeia. Os colonizadores utilizaram uma narrativa, apropriando-se de certas palavras, para subjugar os colonizados. Essas palavras, marcadas pela excessiva adjetivação negativa do colonizado, construíram o poder simbólico dos impérios europeus.

As imagens produzidas pelo conjunto da ideologia dominante para inferiorizar o Oriente em relação ao Ocidente, mas também o negro ao branco, e o colonizado ao colonizador, foram parte de um projeto político das metrópoles, no contexto colonial. Conforme Cabaço, "as leituras polarizadas da sociedade colonial feita pela razão econômica e pela razão política se recompunham também ao nível das ciências humanas" (2009, p. 85). Nesse sentido, a literatura produzida no período colonial cumpriu um papel de ora legitimar a dominação colonial, ora de questionar essa dominação.

Em Moçambique, durante as lutas pela independência, os poetas $(\mathrm{e}$ intelectuais, de maneira geral) que questionaram a ordem travaram tanto a luta política, quanto a luta simbólica. No mesmo momento em que se inscreviam nas guerrilhas pela libertação, organizadas pela FRELIMO ${ }^{1}$,

Frente de Libertação de Moçambique. 
escreviam seus poemas que incendiavam palavras de ordem pela superação da realidade, em nome de uma nova forma social, ou seja, em nome de uma nova estrutura. Por assim dizer, os poetas subvertiam a estrutura colonial ao mesmo tempo em que pautavam uma nova estrutura e buscavam o fim das relações de violência, dominação e opressão. Assim como a luta armada se intensificou em Moçambique, também surgiu a luta com as palavras. Nesse período despontam vários escritores como Noémia de Sousa, Rui Knopfli, Duarte Galvão, Albuquerque Freire, Rui Nogar e José Craveirinha.

As lutas pela independência geraram uma articulação dos escritores que desejavam um mundo liberto da opressão e do colonialismo. A criação literária proporcionou uma intervenção mais organizada no cenário político de Moçambique e, consequentemente, o desejo do novo, expresso em poesia, transbordou para a realidade. José Cabaço (2009) comenta que a literatura anticolonial do período colonial se afirmou "pela denúncia ficcional das iniquidades, das humilhações e das brutalidades da ocupação, alimentou na imaginação dos nacionalistas urbanos a utopia de um amanhã de liberdade que se anunciava" (2009, p. 287). Essa geração, que lutava contra o colonialismo, teve seu grito silenciado pela colonização portuguesa, a exemplo da atividade do poeta José Craveirinha nesse período, Leite comenta que

estava condicionada ao silêncio imposto e à ameaça da polícia política. José Craveirinha enforma por esse motivo, com Rui Nogar, Malangatana Valente, Luís Bernardo Honwana e Orlando Mendes, aquela que poderemos designar por geração do silêncio. Silenciada embora, esta geração sempre se afirmou pela recusa do sistema colonial (...) (LEITE, 1991, p. 21).

Mesmo silenciados, os poetas moçambicanos expressavam em seus textos poéticos o desejo pela liberdade. Os temas abordados na escrita dos poetas que viveram no período colonial convergiam para o anseio de construção coletiva por uma nova sociedade. Desse modo, na mesma medida em que a Europa, e mais especificamente Portugal, produziu uma semântica sobre os colonizados buscando sentenciá-los à colonização, escritores moçambicanos criaram uma outra narrativa, que contestou o colonialismo português. Assim sendo, agentes dominados e dominantes lutavam pelos seus ideais, propondo uma leitura do passado e da história. A literatura foi um terreno fértil que evidenciou os conflitos entre os agentes. Cada palavra foi uma arma utilizada para atacar o inimigo, a fim de restituir poder aos colonizados.

Nesse contexto, a luta dos agentes dominados se tornou uma luta pela recuperação da voz, que foi silenciada pelos colonizadores. Era preciso restituir e ressignificar o território linguístico que foi invadido e cindido pelos agentes dominantes. As estratégias utilizadas pelos poetas se expressavam na reivindicação das línguas locais, na representação do silêncio dos colonizados, que se expressa não como submissão, mas como resistência, e na inscrição de símbolos próprios das comunidades autóctones. Podemos dizer, portanto, que a luta pelas palavras tinha como objetivo acumular poder simbólico aos grupos em tensão. Em "Poemeto" (1980, p. 44), de José Craveirinha, vemos como os agentes dominadores atuam e se organizam enquanto grupo, com o propósito de oprimir outro grupo, para manter sua soberania.

Na cidade calada à força

agora falamos mais.

Que para violar este silêncio

basta porem-nos juntos

na prisão.

(CRAVEIRINHA, 1980, p. 44)

No poema acima é possível observar que existem dois campos apresentados: a cidade e a prisão. Segundo Bourdieu, os campos não 
são neutros, e sim produtos de uma luta constante entre agentes que monopolizam capital e agentes com pretensão à dominação (1989, p. 23). Tanto a prisão quanto a cidade são espaços de luta objetiva e simbólica, sendo possível observar que a luta objetiva está representada no verso "na cidade calada à força". 0 poeta mostra a cidade colonial nua, sendo a violência sua característica intrínseca, pois "As relações humanas (no colonialismo) resultam de uma exploração tão intensa quanto possível, fundam-se na desigualdade e no desespero, garantidas pelo autoritarismo policial" (MEMMI, 1977, p. 64). Essa violência não é ocultada; ao contrário, é visível e celebrada. "Vê-se que o intermediário do poder utiliza uma linguagem de pura violência. [...] exibe-as, manifesta-as com a boa consciência das forças da ordem" (FANON, 1968, p. 28).

Assim como a violência objetiva está representada no poema, é possível analisar que a simbólica também se manifesta. O silenciamento da língua e da voz é uma forma de violência simbólica, na medida em que silenciar os agentes colonizados é um meio de dominação não-evidente e não-explícita. Portanto, ao romperem o silêncio da cidade, os colonizados, ao falarem mais, enfrentam a colonização. Logo, o ato de falar é um ato simbólico quando se é sistemática e historicamente silenciado. No poema, o falar nasce do silêncio e essa antítese mostra o processo de luta que passa da aceitação (silêncio) à resistência (falar) ao colonialismo.

No poema analisado é possível perceber que apesar da censura, os sujeitos poéticos agora "falam mais". Quanto mais repressão ocorre, mais a voz teima em ecoar. Essa voz se apresenta enquanto sujeito oculto (nós), mostrando que existem grupos atuando. O poeta reestabelece uma coletividade que foi fraturada pelo colonialismo. Se a narrativa colonial almejou fragmentar o corpo do colonizado, reduzindo sua corporalidade ao trabalho, negando sua voz, Craveirinha aqui recompõe a totalidade dos colonizados, reabilitando a identidade do grupo. Ao utilizar a palavra "juntos", o eu poético afirma-se perante um grupo, excluindo as possibilidades de ação individual. Bourdieu comenta que as ações sociais (desde o gosto pelas coisas até as disposições morais) são dadas pelas condições de existência e não pelas escolhas individuais racionais. A luta coletiva pela voz dá o tom do poema, demonstrando a representação da luta e resistência simbólica.

Lemos o poema "Tempos de rusgas" (1980, p. 87-88), do mesmo autor. I

Era tempo de rusgas.

Havia ordens terminantes

mas era preciso não andar desarmado.

A revista nas estradas era intensa.

Bem armado

passei sem licença de porte de arma

minha mão comprimindo no bolso

as coronhas de 3 poemas.

(CRAVEIRINHA, 1980, p. 87).

O poema abre-se com o verso "Era tempo de rusgas". O eu poético demonstra a situação de conflito que se expressa em "ordens terminantes" e "a revista nas estradas era intensa". No entanto, esse agente está armado, o que possibilita a análise de que o mesmo está subvertendo a estrutura, pois, ele rompe com a ordem. Nessa estrofe, o poeta cria um clima de tensão ao pontuar a antítese desarmado e armado. Se a estrutura exige que é preciso estar desarmado e o eu poético se arma, ele está resistindo ao confrontar o que é estabelecido.

Apenas na terceira estrofe é que verificamos que o agente está armado com poemas, nos levando a inferir que as palavras também são armas contra a ordem. O uso da palavra "coronhas" também cria o jogo entre a 
arma objetiva (utilizada na luta direta) e a arma simbólica (as palavras, a linguagem, a arte).

II

Os que não são poetas

ignoram o que é estarmos em reclusão

armados de conluios até os dentes.

E na sua imprevidência

não sabem que um poema detido

mesmo de cor na cabeça

também é uma forma

dialéctica

de lhes armar o cerco.

(CRAVEIRINHA, 1980, p. 87).

Na segunda parte do poema é possível notar que o sujeito poético se revela como o escritor, ou seja, a voz não é mais de uma personagem, mas é uma voz assumida pelo próprio poeta ao pautar o trabalho metalinguístico. Assim, ele entra no campo da parcialidade ao defender uma perspectiva política de análise e luta, posicionando-se no conflito entre os grupos. Para Sartre, o escritor engajado "sabe que a palavra é ação: sabe que desvendar é mudar e que não se pode desvendar senão tencionado a mudar. Ele abandonou o sonho impossível de fazer uma pintura imparcial da sociedade" (2015, p. 29). É nessa perspectiva de parcialidade e tomada de posição no campo que o escritor reconhece a importância do seu trabalho na luta simbólica ao mencionar que o poema é uma forma de "armar o cerco". O fazer poético pode ser tão revolucionário e importante quanto o fazer logístico da guerrilha, pois, a palavra pode contribuir no processo de consciência dos agentes em luta.

Em "poema detido", vemos a censura produzida pelos agentes dominantes ao recusarem a escrita poética dos dominados, que está impregnada de resistência e denúncia. Essa censura se assentou em outros processos históricos, a exemplo das ditaduras militares na América Latina. A classe dominante, que detém o poder econômico e simbólico, sabe o quanto as palavras são capazes de abalar as estruturas sociais.

A posição de Craveirinha no campo se torna clara ao declarar que, em "tempos de rusgas", o poeta anda armado com poemas. O poeta se insere no seio da classe dominada para defendê-la tanto objetivamente, pois ele participou ativamente das guerrilhas pela independência de Moçambique, quanto simbolicamente, ao arquitetar sua produção poética vinculando uma semântica que combateu a opressão colonial.

III

Sou daquela raça

dos revolucionários mais perfeitos.

A raça dos homens ao natural

que amam o amor sem as mil

fictícias boas maneiras burguesas.

Raça

dos revolucionários mais puros

no amor à beleza feminina

na adoração pelas crianças

no respeito à velhice

no ódio à mendicidade.

Raça de revolucionários cheios de defeitos

e apenas uma pequeníssima qualidade:

Mesmo inseridos em molduras de alvenaria

com uma força de segurança no exterior

não compramos o Amor

e não nos vendemos!

(CRAVEIRINHA, 1980, p. 88).

Nessa terceira parte o poeta escancara o segmento social que combate ao utilizar a expressão "maneiras burguesas", que entra em conflito 
com o segmento social do poeta, "os revolucionários". Nestas últimas estrofes, podemos perceber o habitus proposto por Bourdieu (1989, p. 59). Segundo o teórico, habitus são princípios interiorizados pelo corpo, resultados da experiência histórica, da biografia do sujeito e da interação das experiências. Craveirinha descreve o habitus dos revolucionários que amam o amor, as crianças, a velhice e lutam contra a pobreza. As mulheres, crianças e velhos expressos em beleza feminina, crianças e velhice também devem ser considerados na análise. Esses agentes, na estrutura colonial e no pensamento dominante, estão reclusos da participação social, pois são considerados improdutivos. Quando Craveirinha recolhe essas personagens, trazendo uma relação de alteridade entre estes e os revolucionários, o poeta opera com a reconstituição da totalidade da coletividade. Ao poeta cabe restituir as palavras dos agentes dominados, dando-lhes voz e visibilidade para construírem sua própria história.

O poeta também opera com a contradição dos revolucionários, ao apresentar a forma e conteúdo dos revolucionários que são "mais perfeitos", "mais puros" e simultaneamente "cheios de defeitos", atuando com a lógica dialética, aproximando contrários em uma mesma forma. Ao final, vemos que o escritor fala sobre como o amor é inerente aos revolucionários. Para Bourdieu, as relações entre agentes não são propriamente escolhas, mas resultados de fenômenos sociais. Podemos inferir, portanto, que o amor é derivado de uma estrutura, logo, a mudança de estrutura poderia mudar substancialmente o que entendemos por amor, estabelecendo um diálogo com Craveirinha que critica o amor burguês. A forma de amar burguesa pode ser considerada, por conseguinte, uma violência simbólica na medida em que a classe dominante cria um certo pensamento fictício sobre o amor que é naturalizado pelos agentes em campo e incorporado ao habitus. Craveirinha, na contramão do pensamento hegemônico, propõe subverter o amor dominante.
A escrita de Craveirinha está condicionada a uma posição de classe em um campo da estrutura. Adotando a perspectiva dos colonizados, o poeta reivindica a voz que foi silenciada pelos colonizadores que se utilizaram da violência simbólica, recompondo o corpo dos colonizados, reestabelecendo uma nova narrativa sobre a colonização.

Vemos como ocorre a violência simbólica e a luta pelo poder simbólico em "Súplica", de Noémia de Sousa.

Tirem-nos tudo,
mas deixem-nos a música!

Tirem-nos a terra em que nascemos, onde crescemos

e onde descobrimos pela primeira vez

que o mundo é assim:

um tabuleiro de xadrez...

(SOUSA, 2001, p. 37).

O poema abre-se com "tirem-nos". O "nos" insere a qualidade de grupo, como vimos anteriormente nos poemas de Craveirinha. Essa é uma idiossincrasia da poesia anticolonial produzida nos países de língua portuguesa. Nota-se, em vários poemas, o uso da primeira pessoa do plural, ecoando uma coletividade. Se a Europa partilhou a África, não apenas geograficamente, mas recortou e retalhou corpos, grupos e famílias, ao inscrever "nós" no poema, vemos uma reconfiguração da unidade do grupo, em uma busca por unir aquilo que a Europa fragmentou.

Os sujeitos poéticos recorrem à "música" como patrimônio simbólico, que faz parte do capital cultural, e os mesmos suplicam pela manutenção desse bem simbólico. Na segunda estrofe o tom de lamento prossegue direcionado agora para a "terra". Essa terra carrega consigo memórias daqueles que a habitavam. É nesse ato de relembrar o passado e a ancestralidade que se constrói a ideia de símbolo, entrelaçando reminiscências e subjetividades. 
A terra torna-se elemento simbólico, pois carrega o gérmen da vida e do passado, mas é também elemento econômico, na medida em que as comunidades dependem dela para sobreviverem. As geografias tornam-se um capital econômico e simbólico.

A segunda estrofe apresenta o "tabuleiro de xadrez". Esse tabuleiro sugere a metáfora do mundo colonial, pois, nesse jogo observamos dois grupos que lutam para derrotar seus oponentes. A própria configuração do xadrez demonstra o conflito e as hierarquias dos grupos sociais. Outra metáfora sugerida no poema é a discussão racial que foi latente na colonização portuguesa. As peças do xadrez se dividem em peças brancas e pretas, projetando os conflitos raciais entre negros e brancos. 0 poema continua...

Tirem-nos a luz do sol que nos aquece,

a lua lírica do xingombela ${ }^{2}$

nas noites mulatas

da selva moçambicana

(essa lua que nos semeou no coração

a poesia que encontramos na vida)

tirem-nos a palhota - humilde cubata

onde vivemos e amamos,

tirem-nos a machamba ${ }^{3}$ que nos dá o pão,

tirem-nos o calor de lume

(que nos é quase tudo)

- mas não nos tirem a música!

(SOUSA, 2001, p. 37).

Os sujeitos poéticos clamam para que a música seja mantida. A música se apresenta como um elemento condutor da identidade dos dominados, sendo um importante instrumento de poder simbólico. A súplica torna-se canto. Esse canto inscreve os elementos do espaço moçambicano. Ao inscrever esses elementos, Noémia reabilita a memória da comunidade.

\footnotetext{
${ }^{2}$ Dança tradicional.
}

3 Dança traão.
O título sugere que os sujeitos poéticos se sentem impotentes diante da estrutura que os oprime, mas dialeticamente surge uma força que se instala no subterrâneo no texto de Noémia. É a partir da música que os colonizados passam a resistir, pois, nela encontram sua identidade e sua memória, que vão servir de combustível para a luta concreta contra os colonizadores.

Podem desterrar-nos,

levar-nos

para longes terras,

vender-nos como mercadoria,

acorrentar-nos

à terra, do sol à lua e da lua ao sol,

mas seremos sempre livres

se nos deixarem a música!

Que onde estiver nossa canção

mesmo escravos, senhores seremos;

e mesmo mortos, viveremos,

e no nosso lamento escravo

estará a terra onde nascemos,

a luz do nosso sol,

a lua dos xingombelas,

o calor do lume,

a palhota onde vivemos,

a machamba que nos dá o pão!

E tudo será novamente nosso,

ainda que cadeias nos pés

e azorrague no dorso..

E o nosso queixume

será uma libertação

derramada em nosso canto!

- Por isso pedimos,

de joelhos pedimos:

Tirem-nos tudo.

mas não nos tirem a vida,

não nos levem a música!

(SOUSA, 2001, p. 38). 
A música gera a força para resistir ao mundo colonial. Ela é o gérmen que vai pôr fim a esse mundo e construir um novo mundo. A partir dela, serão restituídos todos os elementos simbólicos e econômicos dos colonizados. É interessante perceber a relação entre a música e resistência. Os movimentos anticoloniais foram fortemente influenciados pelo pan-africanismo e pelos movimentos negros. Nos Estados Unidos, por exemplo, no começo do século XX, houve um movimento cultural chamado de "Renascimento do Harlem", que surgiu nesse bairro negro de Nova York, que propôs um resgate as raízes culturais africanas. Desse modo, várias músicas, peças de teatro e intervenções artísticas foram produzidas unindo ritmos cosmopolitas a tambores e ritmos tribais. Além de uma identidade estética que foi criada nesse período, fortaleceram-se também as questões políticas. A música, portanto, é um elemento visceral da resistência negra em diversos momentos da história. Noémia, ao pautar a música no poema, está dialogando com os movimentos negros e também com o passado moçambicano, pois a música é uma substância presente nos rituais, na guerra e nas celebrações.

Vemos também, no poema, a memória da escravidão expressa em "vender-nos como mercadoria", que já traz em si os elementos de um capitalismo emergente, onde a força de trabalho é uma mercadoria no processo produtivo. Essas palavras demonstram que existe um grupo que domina e um grupo que é dominado, como vimos na metáfora do xadrez. Os interesses da classe dominante são incompatíveis com os da classe dominada.

Por último, é possível observar o canto que se torna um elemento interessante para pensar a resistência dos colonizados, podendo ser uma arma de luta na disputa pelo poder simbólico, como vemos nos versos "E o nosso queixume/ será uma libertação/ derramada em nosso canto!”. O canto é um elemento simbólico que ecoa a resistência - e será a chave da libertação dos colonizados.
Esse canto sugere uma relação com a dança (xingombela) inscrita no poema de Noémia, sendo possível observar que a resistência pode se instalar tanto na luta concreta, mas também pelo canto, dança e festa. Assim, os sujeitos poéticos em Noémia propõem resistir pela música, que não muda o mundo, mas abastece as almas e os corpos, organismos que mudam o mundo. Dança e canto são capitais simbólicos que estão em disputa. Se o ballet e a ópera são considerados elementos culturais mais nobres que outras formas artísticas é porque um grupo social legitimou tal pressuposto. Para que essa legitimação ocorresse foi preciso negar e silenciar outras manifestações da dança e da música de outros grupos sociais. Dessa forma, se estabelece a luta pelo capital simbólico. 0 canto e a música irrompem na "cidade calada à força" como resistência ao colonialismo.

Nos três poemas analisados, vemos como a voz, a poesia e a música são capitais simbólicos que - ao serem utilizados na luta simbólica - atuam como peças viscerais pela disputa de poder simbólico. Como notamos, o poder simbólico está diretamente relacionado ao poder econômico, visto que, a posição social do agente no campo é a soma de volume de capital (econômico e simbólico), pesos entre os diferentes capitais e a trajetória social do agente. Portanto, quem detém o poder econômico, possui também o poder simbólico. Assim, os poetas do período colonial enfrentam o colonialismo em duas vias: através da luta objetiva e da luta simbólica. Essas lutas, para Bourdieu, se estabelecem em um campo que é cercado de instituições e dogmas naturalizados.

Compreender a gênese social de um campo, e apreender aquilo que faz a necessidade específica da crença que o sustenta, do jogo de linguagem que nele se joga, das coisas materiais e simbólicas em jogo que nele se geram, é explicar, tornar necessário, subtrair ao absurdo do arbitrário e do não-motivado os atos dos produtores e as obras por eles produzidas e não, como geralmente se julga, reduzir ou destruir. (BOURDIEU, 1989, p. 69). 
Ao falar da luta, das contradições de um campo, de grupos dominantes e dominados, Bourdieu é constantemente acusado de reducionismo, pois os críticos dizem que as teias do poder são muito mais profundas e complexas que o "simplismo" da análise e a polarização entre dois grupos. No entanto, como comenta o próprio teórico, explicar e desnaturalizar instituições, estudar sobre o campo e os agentes que nele estão em jogo, é uma forma de compreender o próprio homem e sua relação intrínseca e extrínseca com a sociedade. A teoria de Bourdieu não se organiza na redução ou simplificação, mas propõe uma análise científica que leva o método à risca $\mathrm{e}$ como cientista da sociedade, por assim dizer, ele se posiciona em um campo, com um determinado grupo de agentes, a fim de subverter e modificar tanto as estruturas estruturantes, quanto as estruturas estruturadas.

Na poesia anticolonial moçambicana, observamos o mesmo movimento de posicionamento no campo. Ao pautar a resistência e luta pelo poder simbólico, os poetas negam a neutralidade, colocando-se em conjunto com os dominados. A luta pelo poder simbólico, entretanto, é jogada pelos dois lados. Enquanto os colonizadores portugueses buscam uma afirmação física e simbólica de sua língua, desbotando as línguas autóctones, os poetas moçambicanos utilizam suas canetas como arma, na recuperação do capital simbólico dos dominados.

\section{3 Últimas palavras}

Os poetas anticoloniais moçambicanos subvertem a estrutura, recontando e recriando a história ao exporem as brutalidades do colonialismo português. Linguagem ácida, verso livre e oralidade compõem o espaço de luta pela voz. Nesse processo, o escritor luta utilizando as palavras para defender um projeto de sociedade, mas também luta com as palavras no ato de construir a poesia, afinal, a luta com as palavras é a luta mais vã, para citar Drummond. Luta com as metáforas, com a sonoridade, movimentando os versos, criando trincheiras poéticas. 0 projeto da poesia anticolonial moçambicana é ético, mas também estético. No compromisso com os agentes dominados, os escritores têm igualmente um compromisso com a palavra.

Os agentes no campo lutam pelas palavras na medida em que elas são um capital simbólico, que garante a identidade e a desreificação dos agentes. Quanto mais capital simbólico um grupo de agentes tem, maior é o seu poder simbólico. Logo, a luta pela palavra se torna tão necessária quanto da luta política, econômica e material. Os poetas moçambicanos do período colonial, que lutam pela independência de Moçambique, nos mostram como é preciso pautar a luta concreta, a guerrilha, mas também, a luta pela palavra, pela voz e pelos símbolos.

\section{Referências}

BENJAMIN, Walter. Escritos sobre mito e linguagem. São Paulo: Duas cidades, 2011. BOURDIEU, Pierre. O poder simbólico. Rio de Janeiro: Bertrand Brasil, 1989.

CABAÇO, José Luís. Moçambique: identidade, colonialismo e libertação. São Paulo: Unesp, 2009.

CRAVEIRINHA, José. Cela 1. Maputo: Edições 70, 1980.

FANON, Frantz. Os condenados da terra. Rio de Janeiro: Civilização Brasileira, 1968.

KI-ZERBO, Joseph. História geral da África I: metodologia e pré-história da África Brasília: UNESCO, 2010.

LEITE, Ana Mafalda. A poética de José Craveirinha. São Paulo: Vega, 1991.

MBEMBE, Achille. Crítica da razão negra. Portugal: Antígona, 2014.

MEMMI, Albert. Retrato do colonizado precedido pelo retrato do colonizador. Rio de Janeiro: Paz e Terra, 1977.

SARTRE, Jean-Paul. Que é a literatura? Rio de Janeiro: Vozes, 2015.

SOUSA, Noémia de. Sangue negro. Maputo: AEMO, 2001.

Recebido em: 21/08/2017.

Aceito em: 16/12/2017. 